\title{
Cervical Cancer pN0 TNM Finding v8
}

National Cancer Institute

\section{Source}

National Cancer Institute. Cervical Cancer pNO TNM Finding v8. NCI Thesaurus. Code C139727.

Cervical cancer with no regional lymph node metastasis. (from AJCC 8th Ed.) 